\title{
Is anticipated seed cutting an effective option to accelerate transition to high forest in European beech (Fagus sylvatica L.) coppice stands?
}

\author{
Andrea Cutini ${ }^{1} \cdot$ Francesco Chianucci $^{1} \cdot$ Tessa Giannini $^{1} \cdot$ Maria Chiara Manetti $^{1}$. \\ Luca Salvati ${ }^{2}$
}

Received: 30 October 2014 / Accepted: 17 March 2015 /Published online: 1 May 2015

(C) INRA and Springer-Verlag France 2015

\begin{abstract}
- Key message Traditional coppice conversion to high forest through periodic thinning requires a long period to attain the regeneration stage. We showed that anticipating seed cutting can accelerate the progression of the stands towards more adult stand conditions, compared with traditional management. The application of different active management options in the same landscape can contribute to increase landscape diversity.

- Context In southern European beech forests, coppice is a widespread management system, especially due to the past uses. The existence of large areas either abandoned or under protracted transitory stage raises questions concerning
\end{abstract}

\section{Handling Editor: Andreas Bolte}

Contribution of the co-authors $\mathrm{AC}$ : coordinating the research project; FC: conceived the idea, running the experiment, analyzing the data, writing the paper; TG and MCM: collecting the data; LS: analyzing the data and writing the paper.

Andrea Cutini

andrea.cutini@entecra.it

Francesco Chianucci

Francesco.chianucci@entecra.it

Tessa Giannini

Tessa.giannini@entecra.it

Maria Chiara Manetti

Mariachiara.manetti@entecra.it

Luca Salvati

Luca.salvati@entecra.it

1 Consiglio per la Ricerca in Agricoltura e l'analisi dell'Economia Agraria-Forestry Research Centre, Viale Santa Margherita 80, 52100 Arezzo, Italy

2 Consiglio per la Ricerca in Agricoltura e l'analisi dell'Economia Agraria-Research Centre for the Soil-Plant System, Via della Navicella 2-4, 00184 Roma, Italy environmental and economic revenues related to the different management options.

- Aims We evaluated the effectiveness of anticipating seed cutting in beech coppices to accelerate the coppice transition to high forest, compared with traditional management (periodic thinning) and natural evolution pattern (unthinned control).

- Methods We used an exploratory analysis of ecological variables related to structure, dynamics, and productivity of the stands (growth efficiency, leaf area index, litter production, transmittance, and canopy heterogeneity), which were monitored during 10 years in beech coppices in Central Italy.

- Results Anticipating seed cutting produced stronger modification in canopy structure, improving growth efficiency as a result of higher resource availability, supporting higher seed production which accelerated the progression of the stand towards more adult stand conditions, compared with traditional management and unthinned control.

- Conclusion The application of different active management options can increase landscape heterogeneity under the conditions in which increasing landscape diversity represents a priority management issue, while simultaneously allowing environmental and economic revenues.

Keywords Coppice management · Thinning · Leaf area index $\cdot$ Conversion $\cdot$ Litter fall $\cdot$ Understory

\section{Introduction}

European beech (Fagus sylvatica L.) is one of the most widespread broadleaved tree species in Europe. Since the species is frequently dominant at higher mountain elevations in Apennines, it is also important for providing environmental functions. As such, sustainable management of beech forests 
is a central issue in many European countries (Aude and Lawesson 1998; Bolte et al. 2007; Brunet et al. 2010; Peters 1997; Scarascia-Mugnozza et al. 2000; Tarp et al. 2000). Although beech has commonly been managed as high forest along its distribution range (Hahn and Fanta 2001), relatively large areas were also managed as coppice for the production of firewood and charcoal, especially in the lower mountain ranges and in southern European countries (Brunet et al. 2010; Hahn and Fanta 2001). Over the last few decades, the improvement of social and economic conditions in mountain communities, increasing use of non-renewable raw materials, and a progressive shift from intensive forest use toward sustainable and protective forest management have produced a decline in overall wood exploitation and lengthening of rotation periods (Cutini et al. 2013; Hahn and Fanta 2001). Moreover, given the role of mountain forests as a defense against natural hazards and for preservation of high-quality water resources, biodiversity conservation and ecosystem services have become increasingly important in recent decades (Brunet et al. 2010; Scarascia-Mugnozza et al. 2000). These considerations supported widespread conversion of many beech coppices into high forests, as commonly observed in many European countries and forest tree species (Cañellas et al. 2004; Di Matteo et al. 2010; Van Calster et al. 2007). This was motivated by a reputation of high forests as a provider of more productive and ecologically functional stands. In addition, the high forest management can provide higher economic profit due to better log quality and higher timber yield compared with regular coppice management (Ciancio et al. 2006). However, although silvicultural treatment of beech coppice in conversion to high forest is well documented (e.g., Hubert 1983), there are still few studies focusing on the effect of various management options, especially in mountainous Mediterranean areas (Ciancio et al. 2006).

In Italy, major portions of beech stands are currently coppice over the traditional rotation period or coppice in a transition stage to high forest (Nocentini 2009). In general, conversion to high forest has been carried out with a progressive reduction of stand density by applying periodic thinning of the shoots, the first one some years after the normal coppice rotation age; the aim is to favor growth of the best shoots and, at the same time, to reduce resprouting. Conversion to high forest is completed with seedling establishment following regeneration felling carried out according to the uniform shelterwood system, but the regeneration stage has rarely been filled in practice (Nocentini 2009), due to the long time required to complete the conversion process. These conditions raise several questions concerning the current management of beech coppice stands. Large part of these forests are currently abandoned or in a protracted transitory stage, both conditions supporting the establishment of homogeneous stand condition at large scales and the relatively slow progression of the stands towards the regeneration stage (Ciancio et al. 2006).
Novel management options need to be tested to fostering stand dynamics to the achievement of the regeneration stage, favoring stand heterogeneity, simultaneously allowing ecological and economic revenues. To achieve these objectives, we carried out an experimental trial to test the effectiveness of anticipating seed cutting to accelerate coppice conversion in beech stands aged 60-70 years, compared with the traditional management. To test this hypothesis, we conducted a field experiment to evaluate the proposed option versus other management options usually adopted in these forest types (i.e., natural evolution pattern and periodic thinnings). In addition, in order to provide an objective and comparable thorough analysis of the influence of the surveyed management options, we performed a long-term (10 years) analysis of growth efficiency (Waring 1983), canopy structure, and stand heterogeneity. Providing insights toward understanding of the ecological base of forest conversion processes and evaluating advantages and disadvantages of various management options can inform guidelines for managing beech forests originating from coppice. This advanced knowledge may also contribute to prevent the establishment of very homogeneous conditions at large scale.

\section{Materials and methods}

\subsection{Study area}

This study was conducted in a mountainous area of central Italy (Alpe di Catenaia; $43^{\circ} 49 \mathrm{~N} ; 11^{\circ} 49 \mathrm{E}$ ), which is a representative of typical forest systems in the northern and central Apennines. The climate in this area is temperate with warm, dry summers and cold, rainy winters. Approximately, $87 \%$ of the area is covered by forests. Deciduous even-aged forests, mainly aged between 50 to 70 years old are prevalent, with beech as the dominant species at altitudes above $900 \mathrm{~m}$. These stands are almost entirely originated from thinnings applied to a former coppice in order to achieve the conversion from coppice to high forest. This silvicultural treatment is commonly applied in beech coppices with standards (balivage intensif; Hubert 1983) to prepare, in the shortest time possible, suitable microsite conditions for natural (seed) regeneration (Ciancio et al. 2006). The best sprouts in terms of vigor, size, and shape are favored by early thinning, which cull the weaker shoots. The forming high standards grow under cover of the released shoots or after regeneration cuttings, which can be carried out by shelterwood or selection cutting depending on the targeted final stand structure. In the uniform shelterwood system, i.e., the traditionally applied system in pure even-aged beech stands, regeneration cuttings usually consist of seed cutting, secondary, and final cutting. With seed cutting, large standards (seed-bearer) are retained to allow seed production since sprouts often did not guarantee a steady provision of seed.

\section{פ̂sriager}


With the other intervention, the gradual opening of the canopy encourages the regeneration of beech seedling at the expense of more light-demanding species like, e.g., oak. Conversion of coppice with standard to irregular broad-leaved stand by selection cutting is a conversion system most frequently adopted for oak species; the system takes advantage of partial or sporadic existing seedling, the object being to provide sufficient light to natural regeneration for further growing.

In this study, the adopted conversion scheme involves the adoption of periodic thinning to gradually reduce the density of the shoots, with the first intervention carried out early after the end of the traditional coppice rotation (usually after a number of years corresponding to $1 / 4$ to $1 / 2$ the traditional coppice rotation age). The adopted thinning is thinning from below (hereafter low thinning) to retain the best shoots (usually one- two shoot(s) per stool) to shape the future high forest crop. Subsequent operations consist of periodic thinning at interval of 15-20 years; the intervening period is characterized by temporary opening in the canopy cover. The final step of the conversion scheme is represented by the regeneration felling. The rotation period of this conversion system is $100-150$ years, depending on soil fertility (Hahn and Fanta 2001; Nocentini 2009).

The study included three permanent 1 ha research plots established in 1972 (Amorini et al. 2010). The plots are located at an altitude of about $1,100 \mathrm{~m}$. The mean annual rainfall and mean annual temperature measured from a weather station located close to the studied plots (La Verna) averaged $1,164 \mathrm{~mm}$ and $9.3^{\circ}$, respectively (1992-2012). The average slope was $15 \%$ with South-West exposure. The plots were chosen within a uniformly managed coppice stands 27 years of age with homogeneous characteristics (Table 1). The plots were close to each other (distance $<2 \mathrm{~km}$ ). The last coppicing was undertaken in the plots in 1945-1946. At the beginning of the experiment (1972), a low number of standards (10-15 per hectare) and a number of 1 to 10 shoots per stool were present. Species composition in each stand was nearly pure (beech contribution $>90 \%$ of basal area). The experimental trial included the natural evolution pattern (unthinned control; hereafter, N.EVO) and two different management options. These were the traditionally used conversion system, which involved periodic thinning, and a proposed novel option combining two periodic thinnings with an anticipated seed cutting.

In the traditional conversion system (hereafter TRAD), three low thinnings were done in 1972, 1987, and 2002. We adopted a medium-heavy thinning intensity because we were interested in fostering stand growth for achieving the regeneration stage; the three thinnings reduced standing basal area by 37,44 , and $29 \%$ in 1972,1987 , and 2002 , respectively.

In the other conversion type (hereafter, SEED), two low thinnings of medium-heavy intensity were done in 1972 and 1987, which were comparable with those undertaken with the

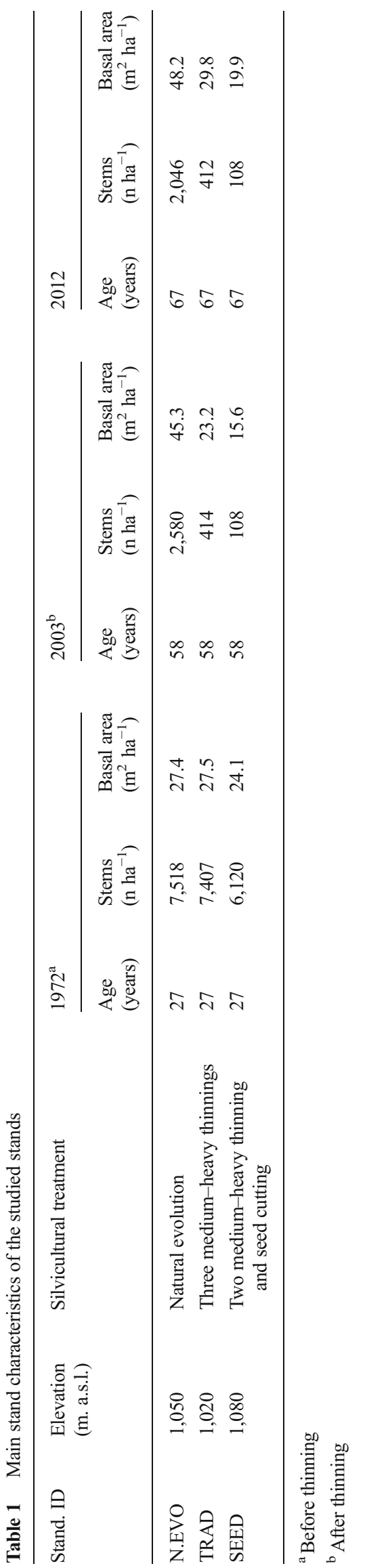


traditional conversion type. In September 2002, an anticipated seed cutting was executed in the plot; the seed cutting was selective and its grade heavy, with reduction of basal area by $56 \%$.

To attain a compromise between long-term monitoring of canopy dynamics and evaluation of the various management options, we were forced to refrain from adding replicates in the original experimental design. Even though we considered differences in canopy properties to be reasonably associated with the different management practices, owing to the longterm observation period, the lack of replicates implies that generalization of the outcome should be carefully evaluated. Table 1 lists the main stand characteristics in each plot.

\subsection{Canopy properties and growth efficiency estimates}

The following variables were estimated in the study plots using various methods: litter production and its partitioning, leaf area index, canopy transmittance, stand heterogeneity, and growth efficiency (Table 2). Previous studies indicated that this canopy attributes exhibit prompt response to disturbances, and are therefore suitable for monitoring the effects of silvicultural practices (Cutini 2002; Rodríguez-Calcerrada et al. 2011). Litter production was estimated using litter traps; Chianucci and Cutini (2013) described the procedure and accuracy of this method. Based on stand homogeneity and structure 9-15 litter traps of $0.25 \mathrm{~m}^{2}$ were laid out in each plot on a grid with spacing 7-20 m, $1 \mathrm{~m}$ above ground level. Litter was collected every two weeks in fall and winter, with the last collection timed soon after the last litter fall. Litter was then sorted into three main components (leaf litter, woody parts, and reproductive parts, with the latter consisting of beech nuts and their husks). Unclassified elements were regarded as "other" components. Litter was then dried to a constant weight in a fan-forced air stove at $85^{\circ} \mathrm{C} \pm 2^{\circ}$. This procedure provides the litter components' biomass $\left(\mathrm{Mg} \mathrm{ha}^{-1}\right)$. With regard to woody parts, this method accommodates small branches and twigs but not large branches (i.e., branches larger than the collector size). Litter was sampled every year in all plots.

Leaf area index was estimated indirectly using the LAI 2000 Plant Canopy Analyzer (PCA; Li-Cor Inc., Lincoln, NE, USA); Chianucci and Cutini (2013) described the procedure and accuracy of the method. The LAI-2000 PCA estimates leaf area index from measurements of radiation transmittance at five concentric rings. PCA measurements were taken in each plot during summer, just after dawn or close to sunset, under diffuse and uniform sky conditions. One abovecanopy reference measurement for each plot was recorded in clearings near each study area. The fisheye lens of the instrument was covered by a $90^{\circ}$ view cap to avoid the influence of surrounding trees on the reference measurements. Belowcanopy measurements were recorded within each plot at the same grid points used for litter collection. Leaf area estimates were obtained using FV2000 software excluding the external ring, to minimize the woody contribution at the largest zenith angle (LAI4). An apparent clumping factor (ACF) was calculated from the software as follows (Ryu et al. 2010):

$A C F=\frac{2 \int_{0}^{\pi / 2}-[\ln \overline{P(\theta)}] \cos \theta \sin \theta d \theta}{2 \int_{0}^{\pi / 2}-[\overline{\ln P(\theta)}] \cos \theta \sin \theta d \theta}$

where $P(\theta)$ is the gap fraction computed for each zenith angle $\theta$. By construction, the ACF is equal to or less than 1 because of the convexity of the $-\ln$ function. Therefore, the greater the

Table 2 Main attributes and climate variables used in the study

\begin{tabular}{lll}
\hline Abbreviation & Method & Description of attribute \\
\hline Leaf_main & Litter traps & Leaf litter of beech \\
Leaf_other & Litter traps & Leaf litter of the other species \\
Woody & Litter traps & Woody litter \\
Nuts & Litter traps & Seed production \\
Husks & Litter traps & Husk production \\
Litter & Litter traps & Total litter production \\
LAI4 & LAI-2000 PCA & Leaf area index \\
DIFN & LAI-2000 PCA & Openness \\
MTA & LAI-2000 PCA & Mean leaf inclination \\
ACF & LAI-2000 PCA & Apparent clumping factor \\
Trasm & AccuPAR ceptometer & Canopy transmittance \\
avgT (JUN-JUL) & Weather stations & Mean temperature during June-July \\
totP (JUN-JUL) & Weather stations & Precipitation during June-July \\
avgT (NOV-DEC) & Weather stations & Mean temperature during November-December \\
totP (NOV-DEC) & Weather stations & Precipitation during November-December \\
\hline
\end{tabular}


degree of clumping, the lower the ACF. This approach estimates clumping effects at scales larger than the single shoot (stand level; Chianucci et al. 2015); hence, the ACF was used as a proxy of stand (structure) heterogeneity. PCA measurements were made every year in all plots, since one summer before the last intervention (2002-2012). Other attributes calculated from PCA included mean leaf inclination (MTA) and canopy openness (DIFN).

Direct canopy transmitted light in the PAR waveband was measured in each plot during summer using the AccuPAR ceptometer (Decagon Devices, Pullman, WA, USA) at midday on sunny days (Chianucci and Cutini 2013). Incident radiation was measured in open areas near the experimental plots. Below-canopy radiation was measured on a grid of 915 sample points that were within $2 \mathrm{~m}$ from the litter traps. For each sample point, four measurements in the cardinal directions were recorded, averaged, and stored in the instruments, for a total of 36-60 readings per plot. Transmittance (Trasm) was calculated as the percentage of below-canopy light, divided by the incident radiation. Canopy transmittance was measured every year in each plot, since one summer before the last intervention (2002-2012).

Growth efficiency $(E)$ was calculated for each plot by combining LAI4 and growth data (Waring 1983). Specifically, $E$ was defined as the ratio of standing basal area increment produced by each plot over a certain period to its mean LAI4, where the standing basal area increment was obtained comparing the two inventories in 2003 (after cutting) and 2012 (Amorini et al. 2010). To assess the effect of different silvicultural management regimes on tree and stand functionality, $E$ was calculated at both stand and tree level (stand data divided by number of trees).

Selected climatic variables were also considered. Since temperature and precipitation can influence significantly canopy attributes (Piovesan and Adams 2001), we collected air temperature and precipitation data on a daily basis from four weather stations in the study area (Table 2) every year during June-July and November-December time intervals, i.e., the extreme periods within the study area. Average air temperature $\left({ }^{\circ} \mathrm{C}\right)$ and cumulated rainfalls $(\mathrm{mm})$ were computed for each period by year.

\subsection{Understory sampling}

Additional measurements were performed to assess natural regeneration of the three stands after 12 years from the last intervention (Chianucci et al. 2014). In August 2014, three $300 \mathrm{~m}^{2}$ understory plots were randomly established within each plot; the understory species were identified and the cover-abundance of each species was estimated using the Braun-Blanquet scale. Understory foliage cover was also estimated in the three stands from a nadir photographic method
(Macfarlane and Ogden 2012; for details see Chianucci et al. 2014). Species richness was calculated for each understory plot.

\subsection{Statistical analyses}

To highlight the influence of the two management systems on canopy dynamics with respect to natural evolution (unthinned control), we used the linear mixed effects (LME) model, with stand silvicultural management as a fixed effect and year as a random effect. When significant differences were observed $(p<0.05), t$ tests were used to investigate which silvicultural treatment differed significantly from each other. Data variability was estimated by calculating the coefficient of variation (CV) for each canopy attribute. A nonparametric analysis (using Kruskal-Wallis $H$ tests at $p<0.05$ after Bonferroni's correction for multiple comparisons) was carried out to compare, for each forest structure variable, the statistical distribution observed in the three treatments.

A factor analysis (FA) based on principal component extraction was run on the available data matrix, composed of 15 variables (see Table 2) and 33 cases observed between 2002 and 2012 for the three silvicultural treatments (TRAD, N.EVO, and SEED). The analysis was aimed at identifying latent patterns among the selected indicators of forest structure in the examined treatments, in relation to certain external control variables (e.g., climatic variables). Components with eigenvalues $>1$ were retained as significant components and analyzed for component loadings and scores. Similarity among variables was ultimately studied using a hierarchical clustering, based on Euclidean distances and Ward's agglomeration rule and performed by standardizing the values of the data matrix subjected to FA. Statistical analyses were carried out using R version 3.0.2 (R Development Core Team 2013) with the "ImerTest" package uploaded and STATISTICA version 7.1 (StatSoft Inc., Tulsa, OK, USA) software.

\section{Results}

Table 3 summarizes the mean canopy properties in the experimental plots during the observation period 2003-2012. The unthinned control showed the lowest annual variability of litter properties. Among the litter components, leaves had the lowest annual variability and reproductive parts the greatest. Leaf litter represented the major litter component in all the plots, contributing to $65-79 \%$ of total litter fall. Woody elements formed the second most important component, 12 $16 \%$ of total fall, with the exception of SEED ( $8 \%$ ). There, fallen wood was less than the production of reproductive parts. Reproductive parts contributed $7-8 \%$ of total litter, again with the exception of SEED, where these parts 
Table 3 Statistics on litter production, leaf area index (LAI4) and canopy transmittance (Trasm) in the studied stands over the 2003-2012 period

\begin{tabular}{|c|c|c|c|c|c|c|c|c|c|}
\hline \multirow[t]{2}{*}{ Stand. ID } & & \multicolumn{6}{|c|}{ Litter components $\left(\mathrm{Mg} \mathrm{ha}^{-1}\right)$} & \multirow[t]{2}{*}{ LAI4 $\left(\mathrm{m}^{2} \mathrm{~m}^{-2}\right)$} & \multirow[t]{2}{*}{ Trasm. $(\%)$} \\
\hline & & Leaves & Woody & Nuts & Husks & Other & Total & & \\
\hline \multirow[t]{5}{*}{ N.EVO } & Average & 3.910 & 0.814 & 0.086 & 0.298 & 0.134 & 5.246 & 6.07 & 1.35 \\
\hline & SE & 0.149 & 0.135 & 0.033 & 0.081 & 0.052 & 0.253 & 0.22 & 0.18 \\
\hline & Min & 2.759 & 0.278 & 0.000 & 0.066 & 0.000 & 3.757 & 4.52 & 0.55 \\
\hline & Max & 4.403 & 1.548 & 0.312 & 0.850 & 0.481 & 6.631 & 6.96 & 2.34 \\
\hline & $\mathrm{CV}$ & 12.1 & 52.6 & 119.7 & 85.9 & 121.6 & 15.2 & 11.6 & 42.6 \\
\hline \multirow[t]{5}{*}{ TRAD } & Average & 3.277 & 0.515 & 0.073 & 0.235 & 0.030 & 4.136 & 4.54 & 6.69 \\
\hline & SE & 0.197 & 0.148 & 0.032 & 0.084 & 0.014 & 0.254 & 0.32 & 1.75 \\
\hline & Min & 1.888 & 0.097 & 0.000 & 0.016 & 0.000 & 2.619 & 2.33 & 1.23 \\
\hline & Max & 4.088 & 1.364 & 0.335 & 0.880 & 0.110 & 5.495 & 5.89 & 16.74 \\
\hline & $\mathrm{CV}$ & 19.0 & 90.6 & 139.4 & 113.6 & 152.4 & 19.4 & 22.1 & 82.8 \\
\hline \multirow[t]{5}{*}{ SEED } & Average & 2.572 & 0.312 & 0.237 & 0.605 & 0.216 & 3.947 & 2.46 & 19.51 \\
\hline & SE & 0.189 & 0.043 & 0.093 & 0.184 & 0.038 & 0.410 & 0.29 & 3.67 \\
\hline & Min & 1.079 & 0.137 & 0.003 & 0.067 & 0.018 & 1.377 & 1.11 & 4.58 \\
\hline & Max & 3.276 & 0.508 & 0.841 & 1.688 & 0.407 & 5.901 & 3.85 & 40.99 \\
\hline & $\mathrm{CV}$ & 23.2 & 43.8 & 123.9 & 96.3 & 55.9 & 32.8 & 49.3 & 63.5 \\
\hline
\end{tabular}

Standard errors (brackets) and coefficients of variation $(\%, \mathrm{CV})$ are reported

contributed $21 \%$ of the total. The remaining fraction of litter ( $\sim 1-6 \%)$ consisted of unclassified elements.

Compared with the unthinned control, the silvicultural treatment had a significant negative effect (LME) on total litter production in both the TRAD $(t$ test, $p<0.05)$ and SEED plots $(t$ test, $p<0.05$ ). Similarly, cutting caused significantly lower leaf production (LME) in both TRAD $(t$ test, $p<0.05)$ and SEED $(t$ test, $p<0.05)$ plots. Leaf litter significantly increased annually in both TRAD (Leaf litter $=0.12 x+2.54 ; n=10, R^{2}=$ $0.51, p<0.05$ ), and SEED (Leaf litter $=0.15 x+1.72 ; n=10$, $\left.R^{2}=0.60, p<0.05\right)$, where $x$ is year; conversely, no significant relationship was found in the unthinned control. Anticipating seed cutting produced significantly higher seed and significantly lower fallen wood (LME and $t$ test, $p<0.05$ ) compared with the other stands.

With regard to LAI4, anticipating seed cutting reduced leaf area by $79 \%$, from $5.23 \mathrm{~m}^{2} \mathrm{~m}^{-2}$ in 2002 to $1.11 \mathrm{~m}^{2} \mathrm{~m}^{-2}$ the subsequent year (Fig. 1). Compared with N.EVO, LAI4 was significantly lower in both the TRAD and SEED plots (LME, $p<0.05)$. Moreover, LAI4 showed a positive annual trend after cutting in both TRAD (LAI4 $=0.26 x+3.37, n=10, R^{2}=$ $0.62, p<0.05$ ) and SEED (LAI4 $=0.30 x+1.12, n=10, R^{2}=$ $0.95, p<0.05$; Fig. 1), where $x$ is the number of year after cutting; conversely, no significant relationship was found in the natural evolution stand.

Compared with N.EVO, Trasm was significantly higher in both the TRAD and SEED plots (LME, $p<0.05$ ). Moreover, Trasm showed a negative trend in both TRAD $($ Trasmittance $=$ $\left.-1.69 x+14.29, n=10, R^{2}=0.85, p<0.05\right)$ and SEED (Trasmittance $=-3.46 x+38.55, n=10, R^{2}=0.81, p<0.05$ ) where $x$ is the number of year after cutting; conversely, no significant relationship was found in the natural evolution stand (Fig. 1).

Growth efficiency $(E)$ illustrated the influence of silvicultural practices on stand growth performance (Table 4). Stand growth rate increased with cutting intensity, ranging from natural evolution to seed cutting. At tree-level size, increasing the cutting intensity produced stands with fewer but larger trees, allowing greater crown enlargement and diameter growth.

The ACF analysis was in agreement with that observed with $E$, indicating that stand heterogeneity increased with cutting intensity (Fig. 2). This was seen as the result of the larger variation of stand structure and canopy properties induced by heavier cuttings. Conversely, natural evolution was characterized by the lowest disturbance, producing a very homogeneous stand as indicated by high and stable values of the ACF.

A nonparametric analysis (Kruskal-Wallis $\mathrm{H}$ tests) was performed to compare, for each selected variable, the median values observed for the three treatments (Table 5). Selected biomass variables were significantly different between the three silvicultural treatments, with Leaf main, Leaf other, Woody, Trasm, LAI4, ACF, and DIFN significantly different in TRAD, N.EVO, and SEED treatments. These results suggest that the various biomass components were influenced differently by the silvicultural treatment in the long term. 


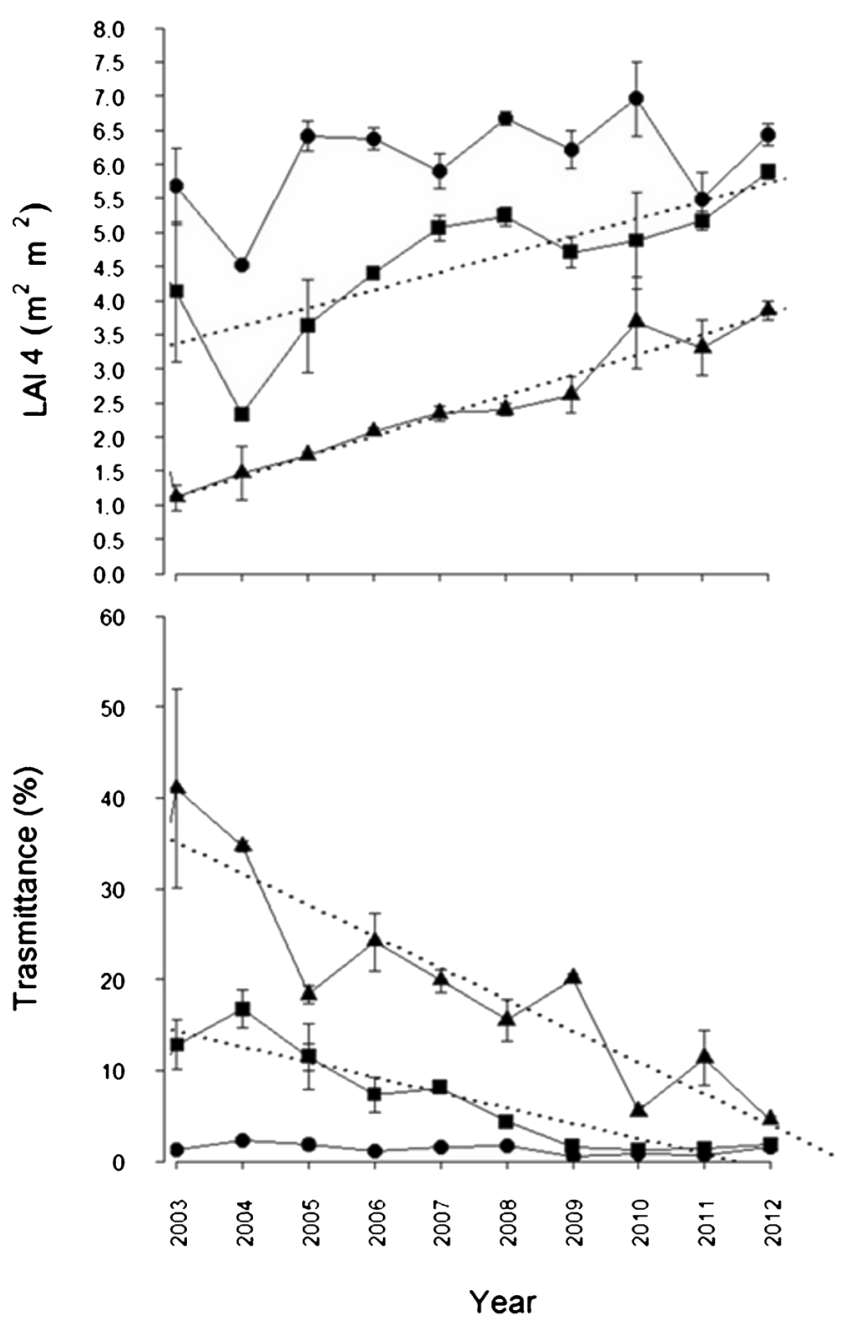

Fig. 1 Leaf area index (LAI4, top) and canopy transmittance (bottom) estimates in TRAD (squares), SEED (triangles), and N.EVO (circles) plots. Standard errors and trends are reported

The factor analysis indicates that the considered indicators had different distributions, structures, and correlations according to the three treatments. Two components were extracted explaining nearly $29 \%$ and $22 \%$ of variance and cumulating the $51 \%$ of the total matrix variance (Fig. 3). Based on the analysis of loading plot (left panel), component 1 represents the biomass variables (Leaf main,

Table 4 Basal area increments $\left(\Delta G, \mathrm{~m}^{2} \mathrm{~m}^{-2}\right)$, average LAI4 $\left(\mathrm{m}^{2} \mathrm{~m}^{-2}\right)$, and growth efficiency $\left(E ; \mathrm{m}^{2} \mathrm{~m}^{-2}\right)$ calculated at both stand and tree level in the studied stands in the period 2003-2012

\begin{tabular}{lllll}
\hline Plot & $\Delta G_{03-12}$ & LAI4 $_{03-12}$ & $E_{\text {stand }}$ & $E_{\text {tree }}$ \\
\hline N.EVO & 2.9 & 6.1 & 0.47 & 0.0002 \\
TRAD & 6.6 & 4.5 & 1.44 & 0.0040 \\
SEED & 4.3 & 2.5 & 1.74 & 0.0161 \\
\hline
\end{tabular}

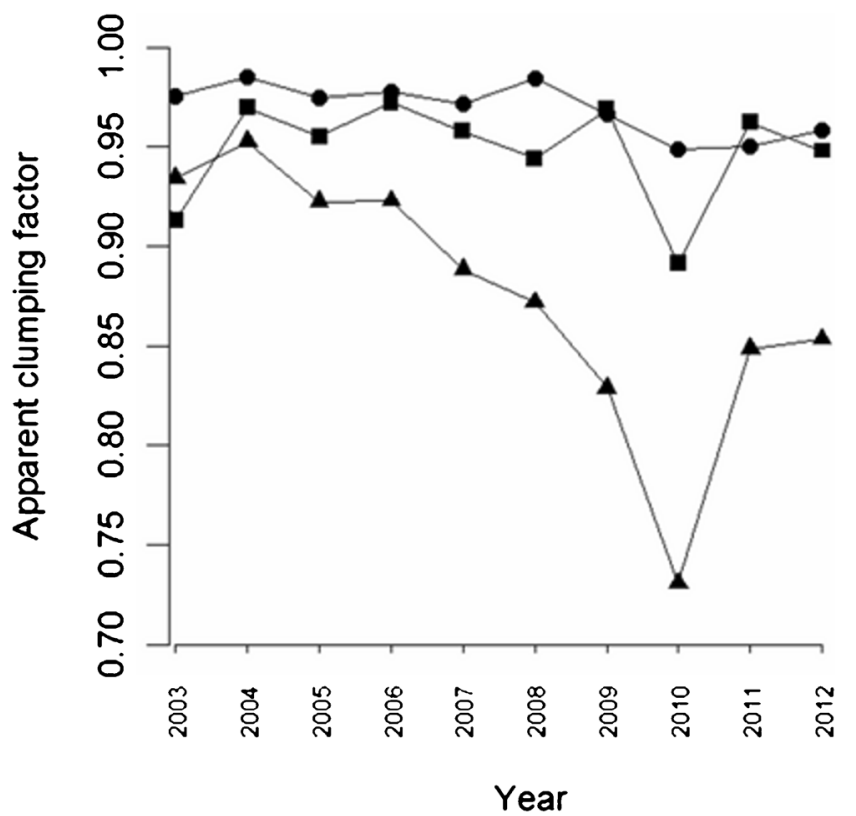

Fig. 2 Apparent clumping factors calculated for TRAD (squares), SEED (triangles), and N.EVO (circles) plots. Standard errors, which varied from 0.01 to 0.02 , were omitted to improve readability

LAI4, and partly, Leaf_other, and Woody were associated with the negative values of the axis while Trasm and DIFN were associated with the positive values of the axis). Nuts and Husks were found uncorrelated with component 1 and associated with component 2. Climate variables were found uncorrelated with any ecological variable, apart from the weak correlation found between TotP (JUN-JUL) and Husks-Nuts. Finally, litter was correlated with both component 1 and 2. The score plot (right panel) indicates component 1 as the most discriminating factor

Table 5 Results of non-parametric tests comparing variables observed for the three treatments (Kruskal-Wallis test)

\begin{tabular}{lcc}
\hline Variable & \multicolumn{2}{l}{ Kruskal-Wallis test $(n=33$, three treatments $)$} \\
\cline { 2 - 3 } & $H$ & $P$ \\
\hline Leaf_main & 16.81 & 0.002 \\
Leaf_other & 16.76 & 0.003 \\
Woody & 9.53 & 0.0085 \\
Nuts & 1.13 & 0.5681 \\
Husks & 2.6 & 0.2718 \\
Litter & 6.94 & 0.034 \\
Trasm & 20.34 & $<0.000$ \\
LAI4 & 24.18 & $<0.000$ \\
ACF & 20.36 & $<0.000$ \\
DIFN & 20.14 & $<0.000$ \\
MTA & 8.06 & 0.0178 \\
\hline
\end{tabular}



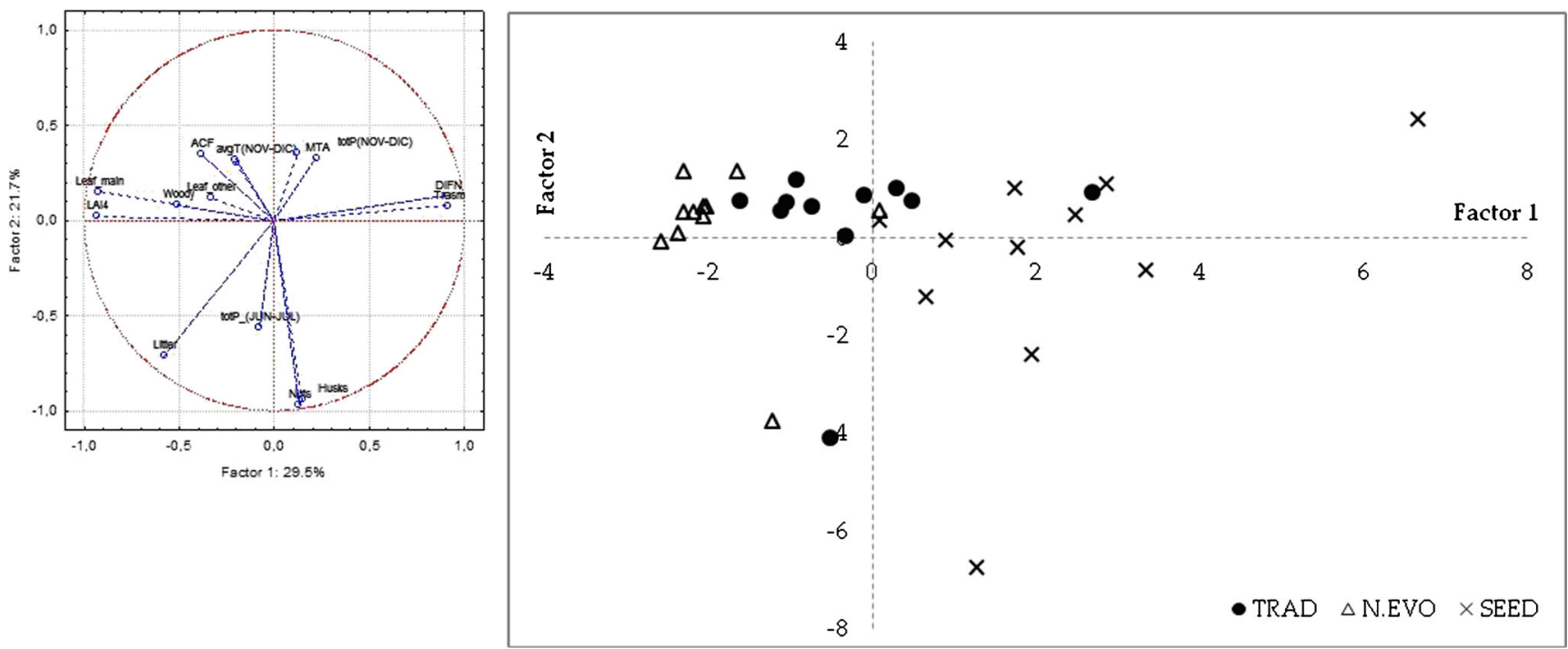

Fig. 3 Results of the principal component analysis identifying latent relationships between structural indicators collected in three treatments (left factor loadings plot, right factor score plot by treatment; see paragraph 2.4 for labels)

among the three silvicultural treatments, forming a gradient with N.EVO clustered along the negative values (with higher values of biomass variables) and SEED clustered along the positive values (with higher values of Trasm). TRAD occupied an intermediate position along component 1.

Hierarchical clustering was done to study the spatial similarity among forest variables (Fig. 4). The dendrogram substantially confirms the previous results obtained by descriptive statistics and FA by identifying two clusters (with minor subgroups) that separate Litter from Leaf variables. In fact, Litter was grouped with Nuts, Husks, TotP (NOV-DEC), Trasm and DIFN. Leaf main was grouped with Leaf other, Woody, LAI4, ACF, MTA, and the other three climatic variables.

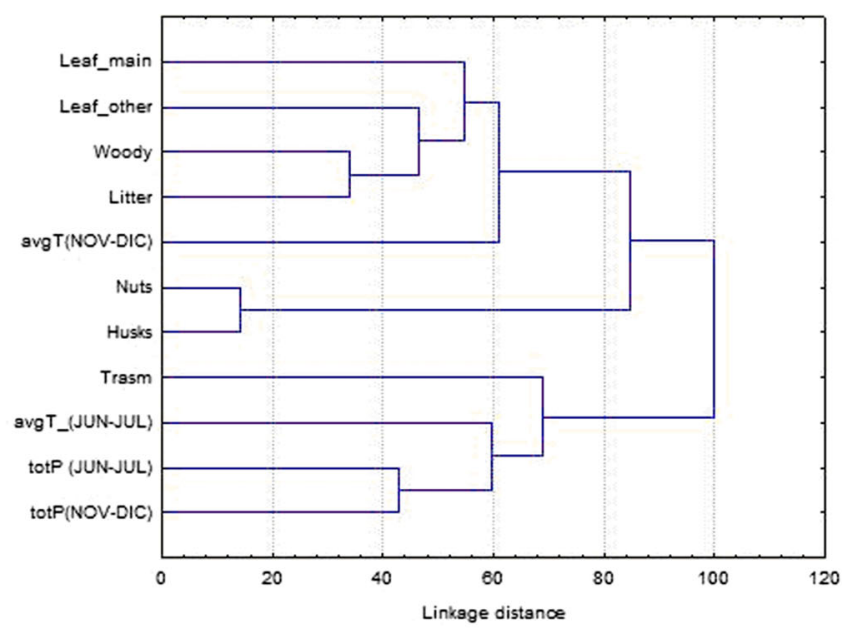

Finally, the three treatments showed different understory attributes. The number of understory species recorded ranged from 16 to 22 in SEED, from 2 to 4 in TRAD and from 1 to 2 in N.EVO. Of these, six tree species were recorded in SEED (Fagus sylvatica L., Quercus cerris L., Abies alba Mill., Prunus avium L., Salix caprea L., Pyrus pyraster L. Burgsd.), with beech being the most abundant species; the average understory height in this plot was $1.5 \mathrm{~m}$. In TRAD and N.EVO, two tree species were observed (Fagus sylvatica L. and Quercus cerris L.); the average understory height in these plots was $0.4 \mathrm{~m}$. The average understory foliage cover in SEED was $0.38 \pm 0.01$ and was significantly larger than those observed in both TRAD $(0.15 \pm 0.03)$ and N.EVO $(0.15 \pm 0.03)$ (Chianucci et al. 2014).

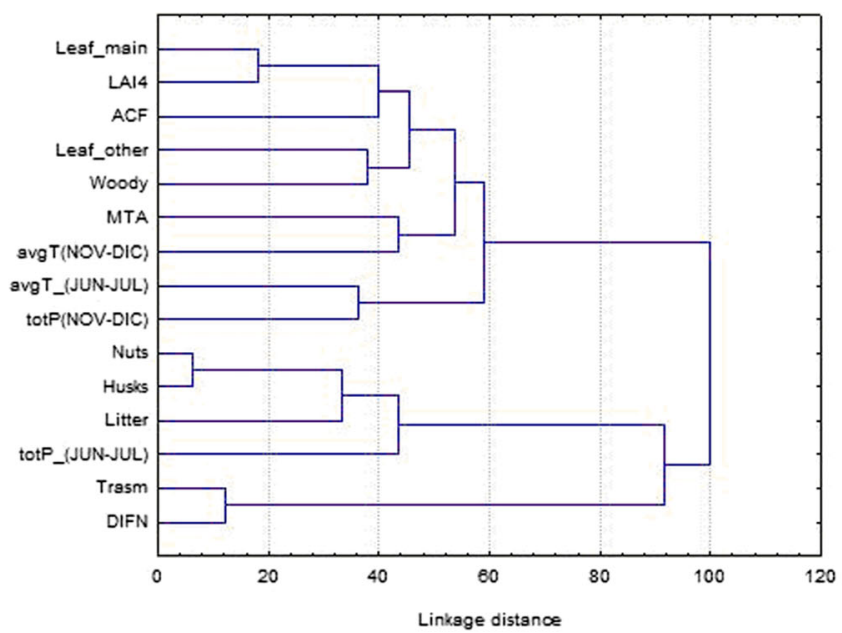

Fig. 4 Similarity among forest variables using hierarchical cluster analysis (left two treatments design, right three treatment design) 


\section{Discussion and conclusions}

Our study revealed that anticipating seed cutting can be an effective management option to accelerate coppice transition to high forest in beech stands aged 60-70 years, compared with the traditional management. To support our hypothesis, we used a long-term, exploratory analysis of ecological indices related to structure, dynamics, and productivity of the stands. All the surveyed variables indicated that seed cutting produced strong modifications in canopy and stand structure, leading to a stand with fewer but larger trees, which were presumably able to intercept more light and to use more water and nutrient (Cescatti and Piutti 1998; Reich et al. 2006); the increased resource availability enhanced tree growth, as outlined by the higher growth efficiency index, supporting larger individual tree crown expansion, and therefore, larger seed production. All these modifications contributed to accelerate stand dynamics to the achievement of a "more-adult" stand structure compared with the other surveyed management options. Conversely, the differences between the traditionally thinned and unthinned stands in the canopy and stand attributes were largest in years immediately after thinning and reached a plateau value over time, resulting in slower progression of these stands towards the high forests, compared with SEED.

A key strength of our study that allowed us to draw this conclusion was that we used a multi-statistical approach to explore the influence of various management options on ecological processes in forest stands; results from all the statistical analyses revealed that the tested variables are influenced differently by the silvicultural treatment in the long-term, demonstrating the effectiveness of the proposed approach to evaluate the effect of various management options on ecological processes in forest stand (Salvati and Zitti 2009). Moreover, the use of ecological variables in our analyses allowed an objective and broadly comparable evaluation of the influence of the applied management options. The selected variables and experimental designs used were in accordance with that of other studies specifically addressing beech forest dynamics (e.g., Chianucci and Cutini 2013; Genet et al. 2010; Lebourgeois et al. 2005; Leuschner et al. 2006; Meier and Leuschner 2008). Based on comparisons with these reports, we conclude that our studied stands are characterized by medium-high productivity, as revealed by the average values of canopy attributes. For example, leaf and total litter values for the unthinned plot were higher than those reported for various beech forests aged 47-200 years (Matteucci et al. 1999), and for beech forests aged 83-147 years in France (Lebret et al. 2001). In addition, leaf area index values were higher than those observed in other Italian beech forests (Cutini 2002), and agreed with those from other studies (Lebourgeois et al. 2005; Meier and Leuschner 2008). This outcome is important because medium-high stand productivity (with reference to canopy attributes) represents one of the main requirements for improving forest management systems, particularly regarding the conversion of coppice woods.

Our results have important implications for designing silvicultural interventions based on ecological criteria. Among the various ecological variables used in our analysis, leaf litter, i.e., the major litter component in all the studied stands, and its correlated attributes like leaf area and canopy transmittance, are the mostly affected by silvicultural practices. Consistently with the standing basal area removal, leaf area decreased by $79 \%$ in SEED and only by $27 \%$ in TRAD while trasmittance increased from $52 \%$ in SEED and only by $18 \%$ in TRAD; the time lag in these stands to fully achieving canopy recovery strictly depended on the different applied cutting intensity. Based on these results, it is possible to prefigure different silvicultural tools for beech woods, depending on the major forest management objectives. From a general point of view, active conversion through medium-heavy thinnings makes silvicultural intervention profitable due to the shortlyrepeated harvesting and intermediate volumes (Amorini et al. 2010). The choice of anticipating seed cutting further accelerate the progression of stands towards the regeneration stage, as demonstrated by the higher growth efficiency value and the significantly larger seed production, which is prerequisite for the achievement of the regeneration stage. Results from understory sampling further supported the effectiveness of anticipating seed cutting with respect to beech seed regeneration (see also Chianucci et al. 2014). Therefore, this option can be regarded as an effective management option in conditions where beech forests have already been largely converted into high stands and in which management policies have produced large homogeneous and widespread transition stands, as frequently observed in many areas of the Apennines (Coppini and Hermanin 2007). When this condition exists, anticipating seed cutting could further accelerate the transition of these stands to the final desired structure, as compared with traditional management. In addition, the combination of different active management option (traditional and anticipated seed cutting) within the same landscape can contribute to increase landscape heterogeneity, favoring the structural diversification of these previously uniformly managed stands, simultaneously yielding more mature stand structure, reducing the risk of disturbances like, e.g., fire and wind throws, and allowing economic revenue from silvicultural interventions (Amorini et al. 2010; Bonnesoeur et al. 2013; Ciancio et al. 2006).

Acknowledgments This study was supported by the Research Program D.M. 19477/7301/08 "Maintenance of collections, databases and other activities of public interest" funded by the Italian Ministry of Agriculture and Forest Policies. Francesco Chianucci was supported by the research grant "Relationship between stand structure and biodiversity in forest ecosystems-ForBIO." We are grateful to Germano Gambi, Emilio 
Amorini and Gianfranco Fabbio for setting up the experimental sites. We are grateful to collaborators and technicians of Forestry Research Centre who contributed to data collection. We thank two anonymous reviewers for helping to greatly improve the manuscript with their comments.

Funding This study was supported by the Research Program D.M. 19477/7301/08 "Maintenance of collections, databases and other activities of public interest" funded by the Italian Ministry of Agriculture and Forest Policies. Francesco Chianucci was supported by the research grant "Relationship between stand structure and biodiversity in forest ecosystems - ForBIO",

\section{References}

Amorini E, Fabbio G, Bertini G (2010) Dinamica del ceduo oltre turno e avviamento ad alto fusto dei cedui di faggio. Risultati del protocollo "Germano Gambi" sull'Alpe di Catenaia (Arezzo). Annali CRACentro Ric Selv 36:151-172

Aude E, Lawesson JE (1998) Vegetation in Danish beech forests: the importance of soil, microclimate and management factors, evaluated by variation partitioning. Plant Ecol 134:53-65

Bolte A, Czajkowski T, Kompa T (2007) The north-eastern distribution range of European beech - a review. Forestry 80:413-429

Bonnesoeur V, Fournier M, Bock J, Badeau V, Fortin M, Colin F (2013) Improving statistical windthrow modelling of 2 Faus sylvatica stand structures through mechanical analysis. For Ecol Manag 289:535543

Brunet J, Fritz Ö, Richnau G (2010) Biodiversity in European beech forests-a review with recommendations for sustainable forest management. Ecol Bull 53:77-94

Cañellas I, Del Rì M, Roig S, Montero G (2004) Growth response to thinning in Quercus pyrenaica Willd. coppice stands in Spanish central mountain. Ann For Sci 61:243-250

Cescatti A, Piutti E (1998) Silvicultural alternatives, competition regime and sensitivity to climate in a European beech forest. For Ecol Manag 102:213-223

Chianucci F, Cutini A (2013) Estimation of canopy properties in deciduous forests with digital hemispherical and cover photography. Agric For Meteorol 168:130-139

Chianucci F, Macfarlane C, Pisek J, Cutini A, Casa R (2015) Estimation of foliage clumping with the LAI-2000 Plant Canopy Analyzer: effect of view caps. Trees 29:355-366

Chianucci F, Puletti N, Venturi E, Cutini A, Chiavetta U (2014). Photographic assessment of overstory and understory leaf area index in beech forests under different management regimes in Central Italy. Forestry Studies | Metsanduslikud Uurimused 61. doi:10. 2478/fsmu-2014-0008

Ciancio O, Corona P, Lamonaca A, Portoghesi L, Travaglini D (2006) Conversion of clearcut beech coppices into high forests with continuous cover: a case study in central Italy. For Ecol Manag 224:235 240

Coppini M, Hermanin L (2007) Restoration of selective beech coppices: a case study in the Apennines (Italy). For Ecol Manag 249:18-27

Cutini A (2002) Litterfall and leaf area index in the CONECOFOR permanent monitoring plots. J Limnol 61:62-68

Cutini A, Chianucci F, Chirichella R, Donaggio E, Mattioli L, Apollonio M (2013) Mast seeding in deciduous forests of the northern Apennines (Italy) and its influence on wild boar population dynamics. Ann For Sci 70:493-502

Di Matteo G, De Angelis P, Brugnoli E, Cherubini P, ScarasciaMugnozza $\mathrm{G}$ (2010) Tree-rings $\Delta^{13} \mathrm{C}$ reveals the impact of past forest management on water-use efficiency in a Mediterranean oak coppice in Tuscany (Italy). Ann For Sci 67:510-518

Genet H, Bréda N, Dufrêne E (2010) Age-related variation in carbon allocation at tree and stand scales in beech (Fagus sylvatica L.) and sessile oak (Quercus petraea (Matt.) Liebl.) using a chronosequence approach. Tree Physiol 30:177-192

Hahn K, Fanta J (2001) Contemporary beech forest management in Europe: Working Report 1

Hubert M (1983) L'amélioration des taillis par balivage intensif. Institut pour le Development Forestier, Paris, p 117

Lebourgeois F, Bréda N, Ulrich E, Granier A (2005) Climate-tree-growth relationships of European beech (Fagus sylvatica L.) in the French Permanent Plot Network (RENECOFOR). Trees 19:385-401

Lebret M, Nys C, Forgeard F (2001) Litter production in an Atlantic beech (Fagus sylvatica L.) time sequence. Ann For Sci 58:755-768

Leuschner C, Voß S, Foetzki A, Clases Y (2006) Variation in leaf area index and stand leaf mass of European beech across gradients of soil acidity and precipitation. Plant Ecol 186:247-258

Macfarlane C, Ogden G (2012) Automated estimation of foliage cover in forest understorey from digital nadir images. Methods Ecol Evol 3: 405-415

Matteucci G, De Angelis P, Dore S, Masci A, Valentini R, Scarascia Mugnozza G (1999) Il bilancio del carbonio delle faggete: dall'albero all'ecosistema. In: Scarascia Mugnozza G (Eds.), Ecologia strutturale e funzionale di faggete italiane, Edagricole, Bologna, pp 133-138

Meier IC, Leuschner C (2008) Leaf size and leaf area index in Fagus sylvatica forests: competing effects of precipitation, temperature and nitrogen availability. Ecosystems 11:655-669

Nocentini S (2009) Structure and management of beech (Fagus sylvatica L.) forests in Italy. iForest-Biogeosci For 2:105-113

Peters R (1997) Beech forests. Geobotany 24, Kluwer, 169 pp

Piovesan G, Adams JM (2001) Masting behaviour in beech: linking reproduction and climatic variation. Can J Bot 79:1039-1047

Reich PB, Tjoelker MG, Machado JL, Oleksyn J (2006) Universal scaling of respiratory metabolism, size and nitrogen in plants. Nature 439:457-461

Rodríguez-Calcerrada J, Pèrez-Ramos IM, Ourcival JM, Limousin JM, Joffre R, Rambal S (2011) Is selective thinning an adequate practice for adapting Quercus ilex coppices to climate change? Ann For Sci 68:575-585

Ryu Y, Nilson T, Kobayashi H, Sonnentag O, Law BE, Baldocchi DD (2010) On the correct estimation of effective leaf area index: does it reveal information on clumping effects? Agric For Meteorol 150: 463-472

Salvati L, Zitti M (2009) The environmental "risky" region: identifying land degradation processes through integration of socio-economic and ecological indicators in a multivariate regionalization model. Environ Manag 44:888-898

Scarascia-Mugnozza G, Oswald H, Piussi P, Radoglou K (2000) Forests of the Mediterranean region: gaps in knowledge and research needs. For Ecol Manag 132:97-109

Tarp P, Helles F, Holten-Andersen P, Larsen JB, Strange N (2000) Modelling near-natural silvicultural regimes for beech - an economic sensitivity analysis. Fore Ecol Manag 130:187-198

Van Calster H, Baeten L, De Schrijver A, De Keersmaeker L, Rogister JE, Verheyen K, Hermy M (2007) Management driven changes (19672005) in soil acidity and the understorey plant community following conversion of a coppice-with-standards forest. For Ecol Manag 241: 258-271

Waring RH (1983) Estimating forest growth and efficiency in relation to canopy leaf area. Adv Ecol Res 13:327-354 